NASA CONTRACTOR REPOR T

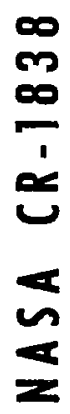

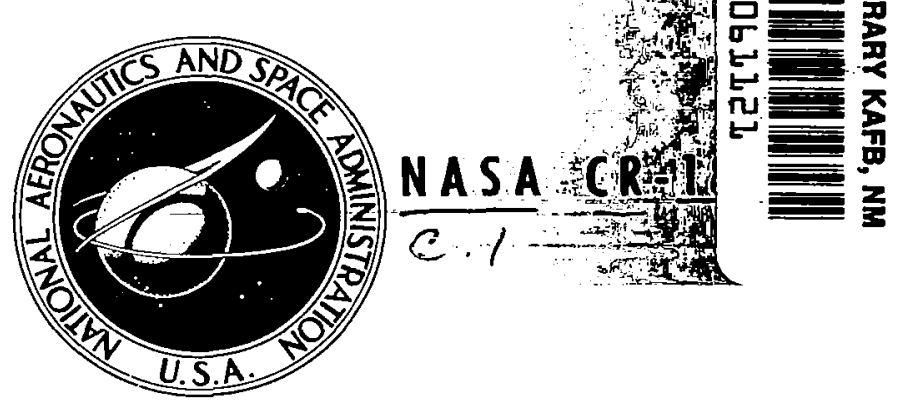

LOAN COPY: RETURN TO AFWL (DOGL)

KIRTLAND AFB, N. M.

\title{
HIGH REYNOLDS NUMBER FLOWS
}

\section{by David A. Russell}

Prepared by

UNIVERSITY OF WASHINGTON

Seattle, Wash.

for

NATIONAL AERONAUTICS AND SPACE ADMINISTRATION - WASHINGTON, D. C. - JULY 1971 


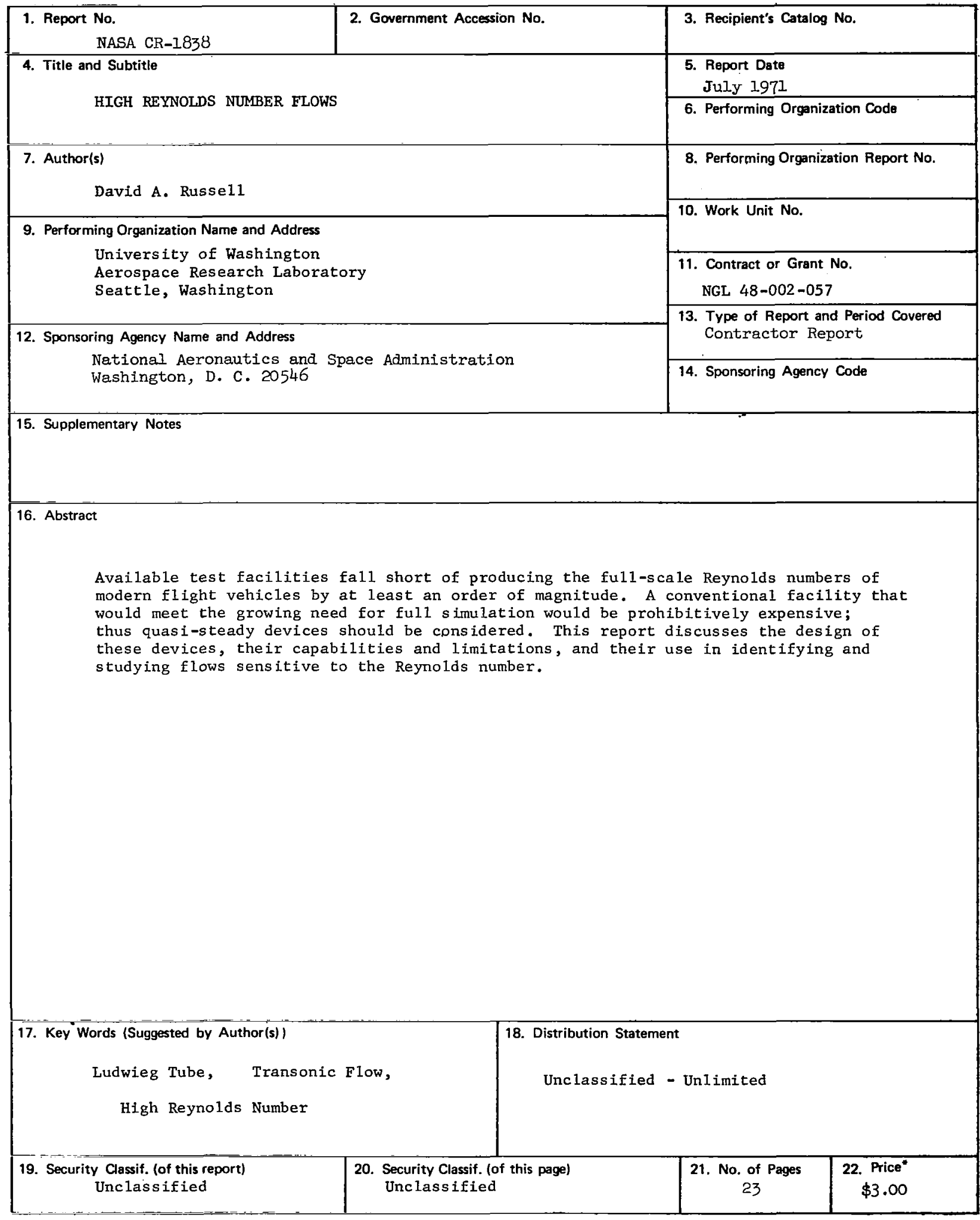

"For sale by the National Technical Information Service, Springfield, Virginia 22151 

FOREWORD

The work discussed in this report was performed at the Aerospace Research Laboratory of the University of Washington under Grant NGL 48-002-057 from NASA Headquarters. The author would like to acknowledge the assistance of $\mathrm{K}$. Tong and $\mathrm{J}$. Stone. A. Hertzberg originated the project, and has had a major influence on its development. 


\section{CONTENTS}

1. INTRODUCTION

2. TEST-FACILITY CONFIGURATIONS

3. TIME CONSIDERATIONS

4. FLOW QUALITY

5. DISCUSSION

6. REFERENCES
Page

1

4

11

14

18

19 


\section{FIGURES}

\section{Page}

1. Re Capabilities and Requirements 2

2. Conventional Ludwieg Tube 5

3. Ludwieg-Tube Performance 6

4. Modified Ludwieg Tube 8

5. Performance of Modified Ludwieg Tube 9

6. Turbulent Boundary-Layer Thickness at Origin of a Centered Expansion Wave 16 


\section{INTRODUCTION}

Most of the aerodynamic testing facilities supporting the major aerospace programs were conceived and developed in the late $1940^{\prime} \mathrm{s}$ and early $1950^{\prime} \mathrm{s}$. While these facilities have been invaluable in the past, recent experiences have revealed inadequacies. Failure in predicting the performance of a modern aircraft can lead to intolerable losses of time, manpower, and economic resources. Test facilities therefore need to minimize this possibility by close simulation of actual flight conditions.

Among the most important similitude parameters for flight vehicle testing are the Mach number (M) and the Reynolds number (Re). $M$ is defined as the flow velocity divided by the speed of sound. A change in this parameter can completely change the nature of the flow around a body. Re is defined as the ratio of the characteristic inertial force to the characteristic viscous force. It measures the relative importance of viscous effects, taking the form of the product of a density, velocity, and length divided by a coefficient of viscosity. The large speeds and sizes of modern flight vehicles lead to extremely large $\mathrm{Re}$, with even larger values to be expected in the future. It is known that high-Re flows involve subtleties that make it difficult to correct for the effects of improper Re-simulation.

Figure 1 shows the present Re capability in this country as a function of test $M$. The figure also indicates typical operating conditions for various modern vehicles. A striking fact is that there is now an order-of-magnitude discrepancy between the Re available and that required. Further, this condition exists over the whole $M$ range and includes such diverse vehicles as VSTOL aircraft, sonic and supersonic transports, and re-entry systems. The discrepancy is caused by the extreme costs involved in proper simulation: a conventional wind tunnel capable of full simulation for a supersonic transport would require a drive motor with over a million horsepower and a national investment approaching one billion dollars! 

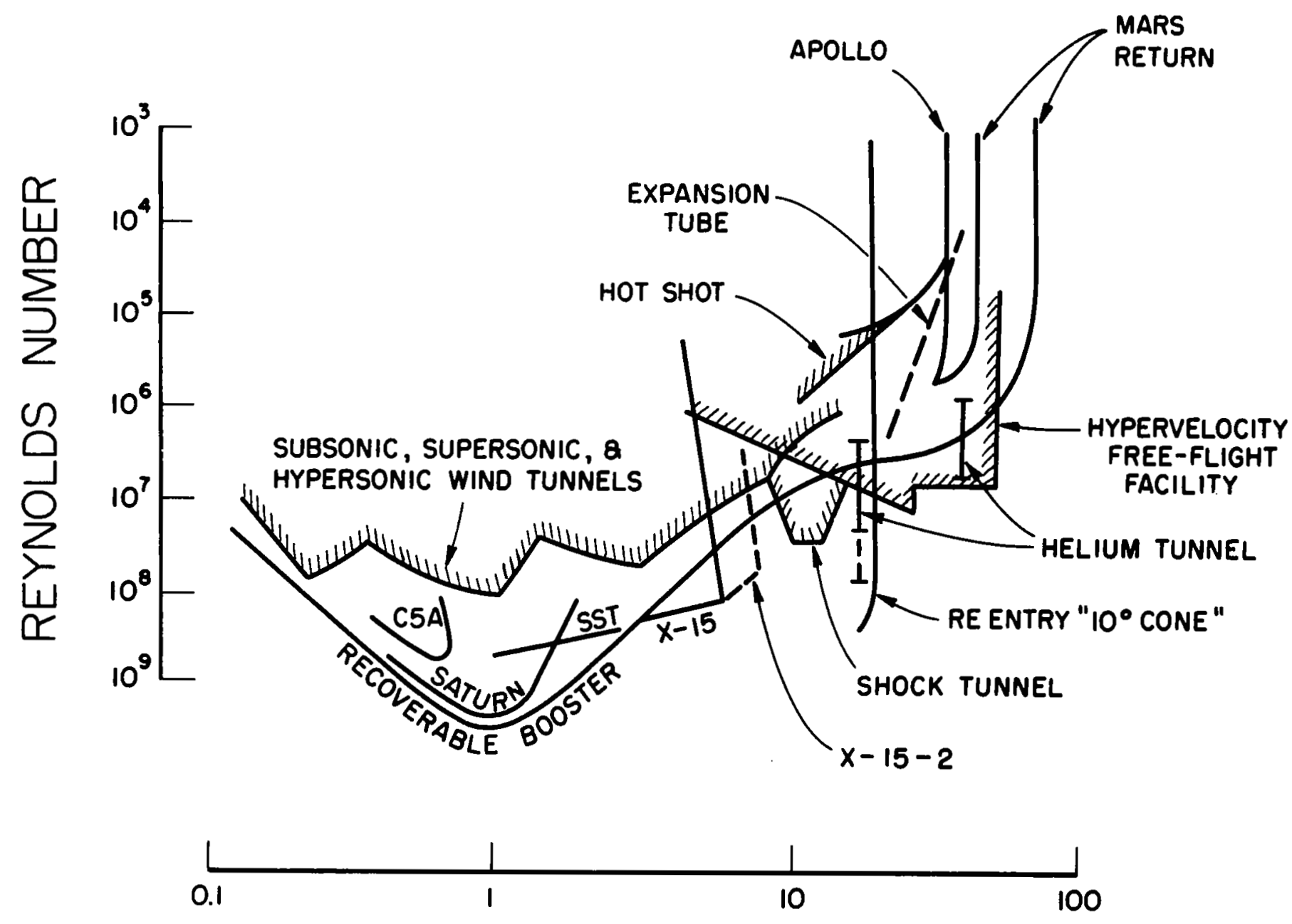

MACH NUMBER

Figure 1. Re Capabilities and Requirements

Figure courtesy of Dr. James E. Danberg formerly with NASA, now with Univ. of Delaware 
While continuous facilities may ultimately be constructed, a likely immediate approach is the use of quasi-steady testing devices. An example is the blow down wind tunnel; however, a more flexible and economical approach may be provided by modifications of the shock-tube devices originally developed for re-entry research. These easily achieve the required $R e$ and $M$ for short periods of time. Since their rate of data production will obviously be low compared with that from conventional wind tunnels, the quasi-steady devices will compliment existing facilities rather than replace them.

The following text discusses various quasi-steady configurations, the problem of insuring sufficient test time, and the test-flow quality that can be expected. The experimental program at the Aerospace Research Laboratory of the University of Washington is then briefly reviewed. While the emphasis here is on the development of practical designs to meet the needs of the aerospace industry, basic studies of high $\operatorname{Re}$ aerodynamics are a major part of the activity. 


\section{TEST-FACILITY CONFIGURATIONS}

In 1955, Ludwieg ${ }^{\text {I }}$ proposed the configuration shown in Fig. 2 as a means of generating high-Re flow. A pressurized tube, the supply tube, is connected to a nozzle and test section. The rupture of a diaphragm causes an expansion wave to propagate down the tube towards the closed end, and a steady flow is soon set up in the nozzle. Subsequent work in the United King$\mathrm{dom}^{2}$ and in Japan ${ }^{3}$ outlined the performance of Ludwieg tubes for investigation of high-Re base flow, ${ }^{4}$ a group in Germany is using heated Ludwieg tubes to study hypersonic flow, ${ }^{5}$ and the NASA Marsha11 Space Flight Center is testing a Ludwieg tube $4 \mathrm{ft}$. in diameter as a pilot for a proposed full-scale facility. ${ }^{6}$ In addition, a group at the Arnold Engineering Development Center has designed a full-scale facility utilizing a cooled drive tube (to increase available $\mathrm{Re}$ ), and there are various aircraft company studies of this type of facility.

The Re capability of simple Ludwieg tubes is illustrated in Fig. 3, where test section Re per foot is plotted vs test section $M$ for a device whose test-section diameter (d) equals the supply-tube diameter $\left(d_{s}\right)$. The supply-tube pressure $\left(P_{4}\right)$ was chosen to be 2000 psi. A comparison with Fig. 1 reveals that such a tube can produce full-flight Re with models having a characteristic length of slightly over one foot. However, there is a serious problem in constructing and supporting models to take the high pressure levels. The wing-root bending stresses can be shown to be directly proportional to the dynamic pressure of the test flow $(q)$. Estimates are that a slender transport wing made of high-strength steel could withstand a $q$ of only $10 \mathrm{psi}$ when operated at a representative angle of attack. The $q$ produced by the simple Ludwieg tube with $\mathrm{P}_{4}$ of 2000 psi is also shown in Fig. 3. Clearly, high-Re testing of conventional flight vehicles will have to be done in large facilities.

A two-stage nozzle configuration being developed at the University of Washington for chemical kinetic studies ${ }^{7}$ may also have useful application to Ludwieg tubes. The design is 


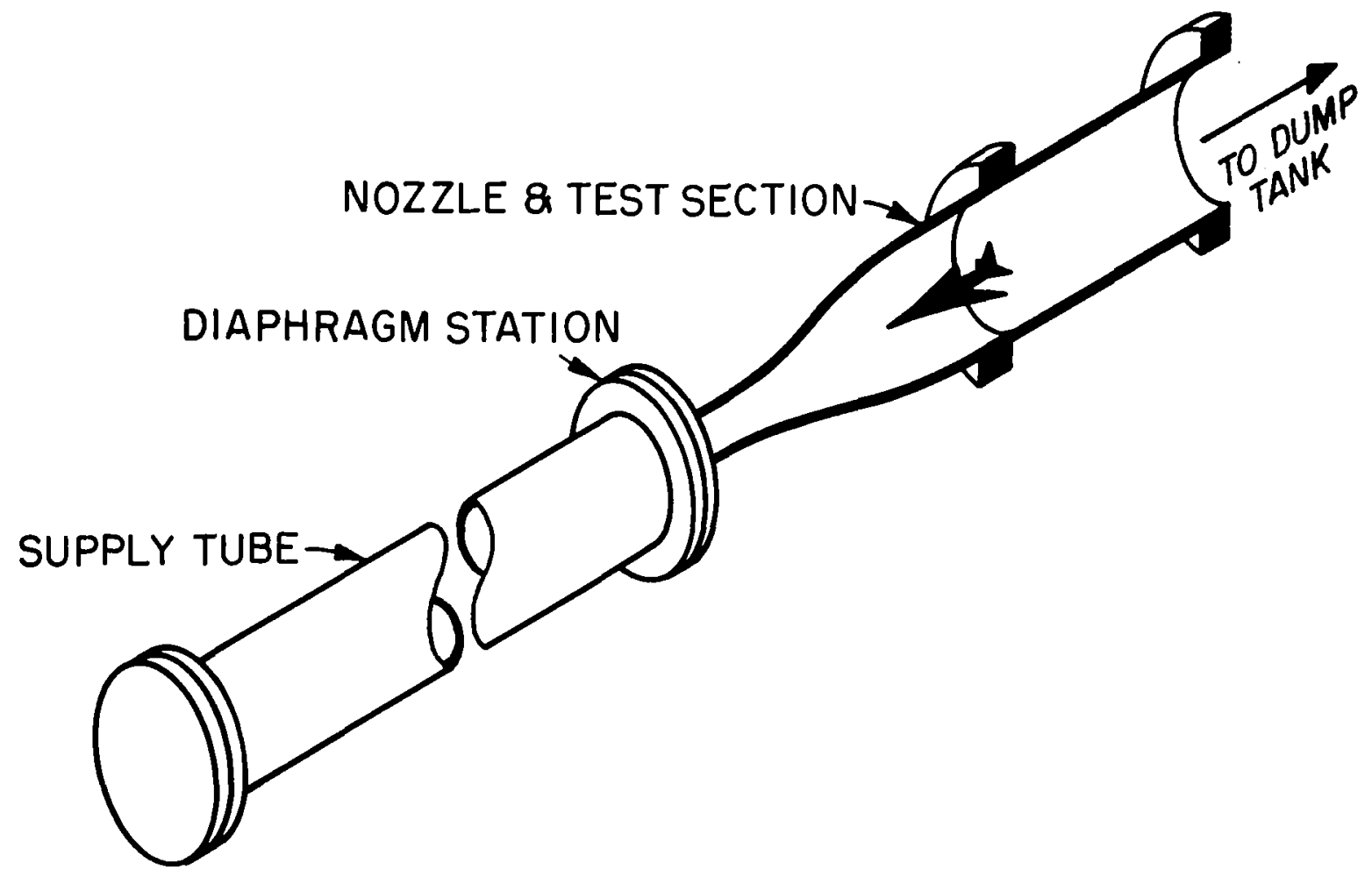

Figure 2. Conventional Ludwieg Tube (Cutaway Nozzle) 


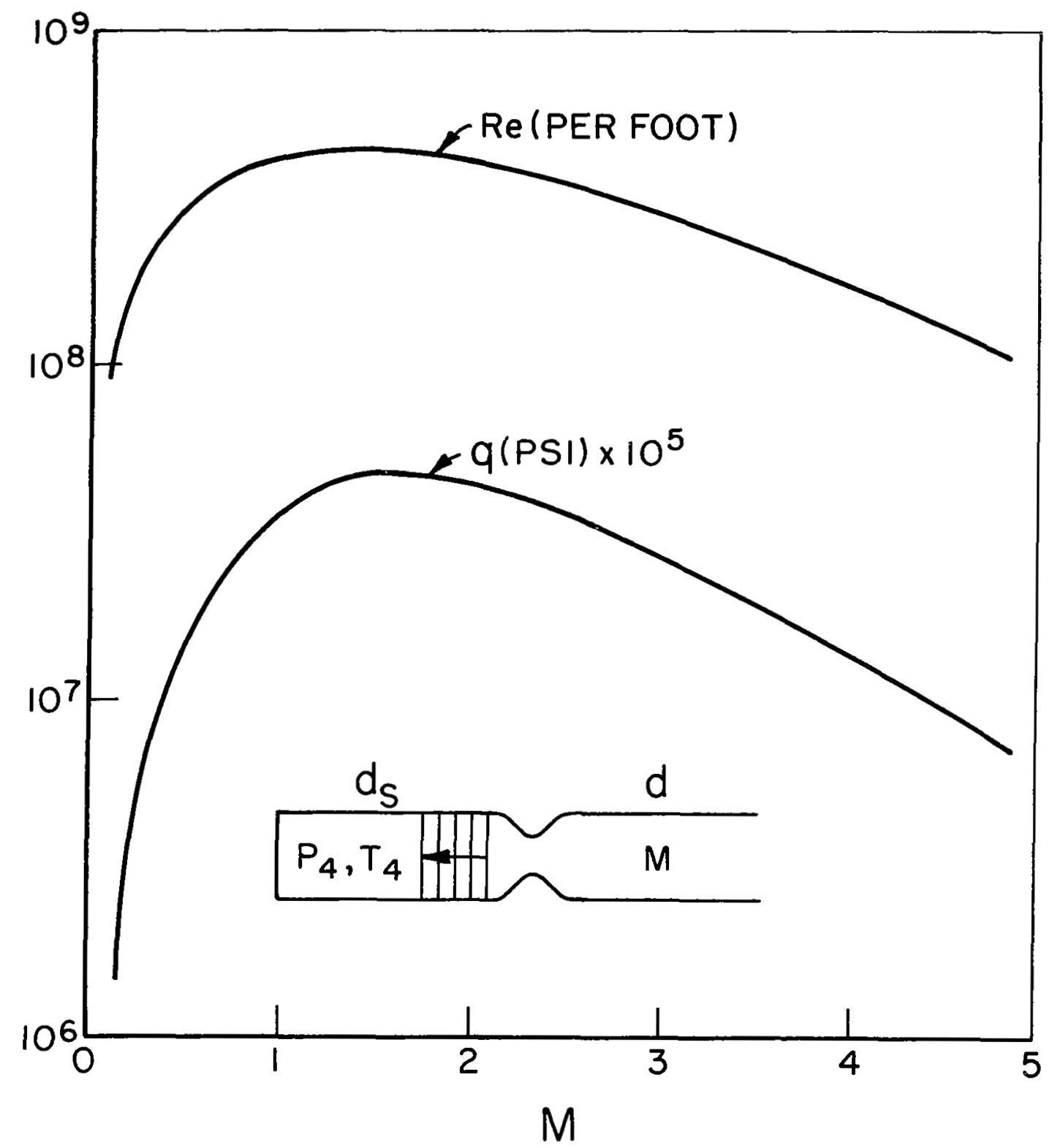

Figure 3. Ludwieg-Tube Performance: Test Section Re/ft and $q$ vs $M$ (Nitrogen: $\mathrm{P}_{4}=2000$ psi; $\mathrm{T}_{4}=300^{\circ} \mathrm{K} ; \mathrm{d}=\mathrm{ds}$ ) 
illustrated on Figure 4. A first-stage nozzle or orifice plate is used to quickly expand the flow from the supply tube to supersonic $M$. If the area of the test-section nozzle throat is made larger than the first-stage throat area, a shock system can be formed between the two throats. This drops the total pressure of the flow, and mass continuity then requires a corresponding increase in the downstream throat area. Pressure capability of the supply tube can thus be traded for increased test-section dimensions, resulting in lower dynamic pressure for the same Re based on $d$. The configuration of Figure 4 was proposed earlier by $\mathrm{Falk}^{4}$, for essentially the same reasons.

The performance of Ludwieg tubes using two-stage nozzles is illustrated by Figure 5, where $\operatorname{Re}$ per unit of $\mathrm{d}_{S}$ and $\mathrm{P}_{4}$ is plotted versus the device geometry. Re is based on freestream properties in the test section and on $d$. The figure is for unheated nitrogen with $M=3$. The ratio of supply-tube diameter to first-stage throat diameter $\left(d_{s} / d^{*}\right)$ is fixed for each solid curve. Increasing the dimensionless test section diameter $\left(\mathrm{d} / \mathrm{d}_{\mathrm{s}}\right)$ with $\mathrm{d}_{\mathrm{s}} / \mathrm{d}^{*}$ fixed requires an increased pressure loss, which in turn decreased $R e$ in spite of the increased $d$. The high $\operatorname{Re}$ end of each curve is where no total pressure losses occur, so that the single line connecting these points corresponds to the performance available from conventional Ludwieg tubes. Lines of dimensionless test-section dynamic pressure are indicated by the dashed lines. It is seen that staging offers large decreases in dynamic pressure for fixed $\operatorname{Re}$ capability. Whereas a conventional Ludwieg tube must use large $\mathrm{d}_{\mathrm{s}}$ and low $\mathrm{P}_{4}$ to keep the dynamic pressure low, the two-stage design uses a small $\mathrm{d}_{5}$ at high $\mathrm{P}_{4}$. The new design may permit the use of components of existing facilities. It may also have the important advantage of simpler and less costly starting diaphragms.

Other test-facility configurations are being considered in addition to the Ludwieg tube and the modified version just discussed. Among these are the use of the gas behind the shock wave in a conventional shock tube, and use of the reflected shock tunnel developed for re-entry research. While the 


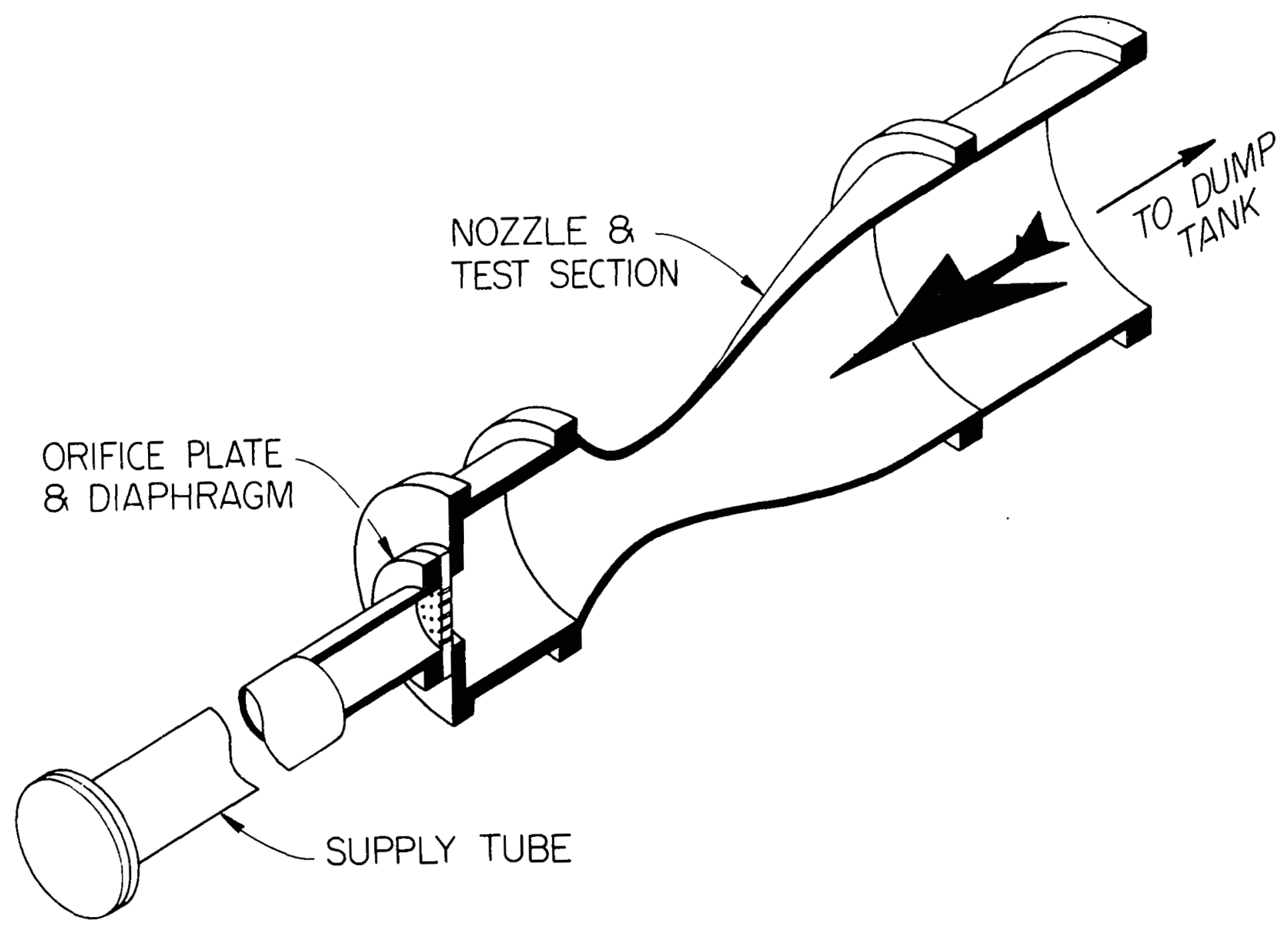

Figure 4. Modified Ludwieg Tube 


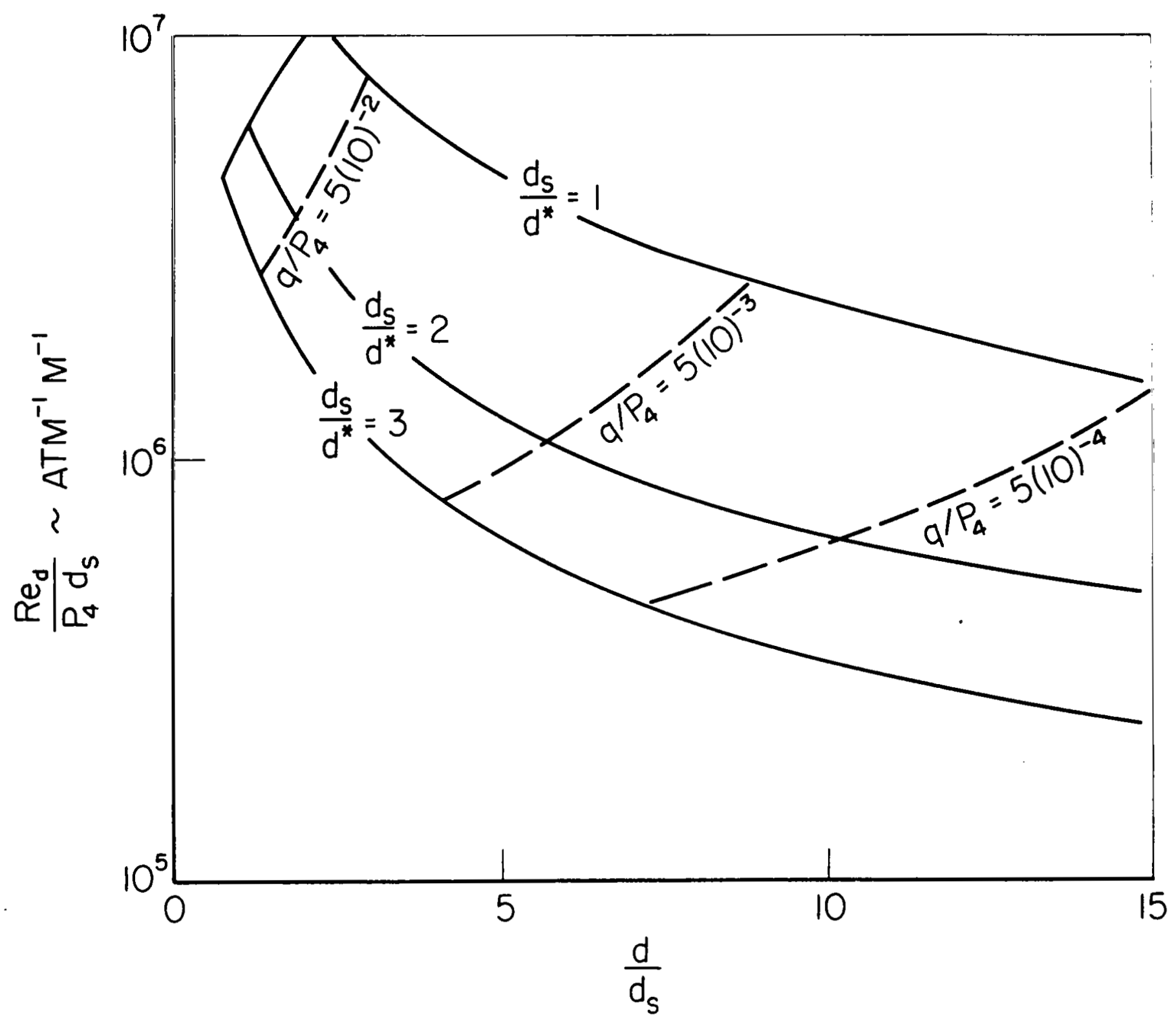
Mach No. = 3; Unheated Air) 
testing times and Reynolds numbers are somewhat reduced with these configurations, they do provide the possibility of correct temperature simulation. It is interesting to note that two-stage nozzles are readily adaptable to the reflected shock-tunnel configuration, and indeed were initially developed to be driven in this manner. 


\section{TIME CONSIDERATIONS}

Quasi-steady facilities will be useful for high-Re studies only if the available test time considerably exceeds the time required to set up steady flow about the model. The maximum available testing time for a Ludwieg tube is the time measured from the diaphragm rupture until the head of the expansion wave has travelled down the supply tube and reflected back again to the test section. This time varies between $1.7-2 \ell / a_{4}$, depending on the strength of the expansion wave. Here $l$ is the length of the supply tube and $a_{4}$ is the undisturbed sound speed. Some of the test time will be taken up with opening the diaphragm and starting the nozzle flow. Generally, the diaphragm opening time is comparatively unimportant, whereas a characteristics calculation has shown that approximately $5 \mathrm{~L} / \mathrm{a}_{4}$ is needed to extract the starting shock from a $M=3$ nozzle with a downstream diaphragm. The nozzle length $L$ must be at least equal to 3-4 exit diameters for uniform flow. Thus, at least $10 \mathrm{~d}$ of supply tube is necessary merely to start the nozzle flow. Hypersonic shock-tunnel studies have shown that nozzles start faster with upstream diaphragms; however, large losses are possible for transonic nozzles with either diaphragm location.

A more serious loss in available time would be expected for the two-stage design. This may also be analyzed by the method of characteristics, but useful information can be obtained through simple mass-flow considerations. It is found that the time taken to reach $90 \%$ of final mean pressure between the stages is equal to $4 \mathrm{~V} / \mathrm{a}_{4} \mathrm{~A}_{2} *$, where $\mathrm{A}_{2} *$ is the area of the second throat and $V$ is the between-stage volume. Shorter starting times are predicted if $\mathrm{V}$ is initially filled to some intermediate pressure, but now strong starting waves would be expected to reflect between the two throats so that the simple analysis may be less useful. The calculation does show the importance of keeping the interstage volume small, and it points to the need to establish how the use of very very small volumes will affect the quality of test flow. Present estimates are that a two-stage design with appreciable d enhancement could take 3-4 times as long to start as the $M=3$ nozzle with the downstream diaphragm and the same exit dimensions. While not a serious limitation in 
itself, this loss must be kept in mind when considering the use of the two-stage design.

In addition to the facility start time, it is necessary to know the time required to establish steady flow about the model. The flow-establishment time for a simple flat plate is reasonably well understood. At zero angle of attack, the inviscid external flow field is established as soon as the plate is fully immersed in the test flow. For a lifting flatplate, time is required to convect the starting vortices sufficiently far downstream that they contribute a negligible influence on the model. While zero influence would require an infinite time, incompressible calculations ${ }^{8}$ suggest that only $10-100$ body lengths are required for all practical purposes. Compressible flow requirements should be even less due to the decreased upstream influence of the starting vortices. Early work on the impulsive motion of a flat plate indicates that on 1 y 2-3 body lengths are necessary to establish a steady boundary-layer. 9 Our approximate calculations for flat-plate flow are in agreement with these results. Recent measurements using heat-transfer gages in a shock tube also indicate that three body lengths are required, even when the boundary layers are undergoing transition to turbulence. ${ }^{10}$ The available calculations need to be refined and checked by more sensitive experiments; however, it seems unlikely that very long flow lengths are needed to establish steady flow about simple flat plates as long as the boundary-layers remain attached.

More complicated models present a somewhat different story. A recent experimental study of the oscillating forces on spheres ${ }^{11}$ shows that more than half of the energy in the fluctuating lift is associated with frequencies whose characteristic length is greater than 100 diameters. Indeed, the maximum spectral density of the fluctuating lift corresponded to wavelengths exceeding 1000 sphere diameters, with $10 \%$ of the energy tied up in longer wavelengths. The long wavelength forces arise through a complex coupling with the large-scale eddies in the wake. Re-sensitive flows may involve such long wavelengths, and thus may require long flow lengths to fully establish. This is certainly true for the type of shock boundary-layer interaction that has been identified as a cause of engine failure on some new aircraft designs. Here many frequencies are involved, including the 
resonant aerodynamic frequencies of the inlet duct itself. There is now some evidence that "organ-pipe" frequencies exist in much simpler separated flows.

A Ludwieg tube with a supply tube $100 d$ long will provide a test flow of approximately $400 \mathrm{~d}$ at $M=3$. The test-flow length drops almost directly with $M$ as $M$ is lowered. The seriousness of the problem of test-length limitations depends on the nature of the model-flow starting process and the degree of precision required of the measurements. 


\section{FLOW QUALITY}

High-quality test flows are required in order to study $\mathrm{Re}-$ sensitive phenomena. For example, investigations of flows involving boundary-layer transition will not represent atmospheric flight conditions unless the test flow has low vorticity and turbulence levels. At high $M$ it may even be necessary to consider noise from the turbulent boundary layers on the wind-tunnel walls. Quasi-steady facilities should provide high-quality flows if care is taken with possible sources of flow vorticity, such as the first stage in the two-stage configuration.

A convenient way to construct the first-stage nozzle is to use a plate with many small orifices, such as indicated in Fig. 4. The underexpanded free jets issuing from the individual orifices will each have an encompassing barrel shock wave terminated by a normal shock (the Mach disc). By comparing the mass flow through the Mach disc with that at the throat, it is found that over $90 \%$ of the flow is through the variable-strength barre1 shock. Although the mean strength of this shock system must be given by the one-dimensional relations, the detailed flow is far from one dimensional. Large entropy gradients are expected that could seriously affect the quality of the flow in the test region. By reducing the orifice diameter as far as strength and viscous loss considerations will allow, the scale of the vorticity will be reduced and the available dimensionless decay length increased. Additional smoothing may be provided through the use of fine screens. Should the orifice or screen grid still produce unacceptable flow quality at the test section, an array of contoured nozzles or perhaps even a single contoured nozzle may have to be used as a first-stage. In the latter case, the throttling shock wave will interact with the turbulent boundary layer to produce a Mach reflection that extends out into the flow. This source of nonuniformity can be removed with boundary-layer bleeding.

The pressure and temperature feeding a Ludwieg tube nozzle are constant in the absence of viscous effects. Becker ${ }^{12}$ has 
studied the supply-tube boundary layer and found that it causes relatively small variations in total pressure (2\%) if the tube is no more than 100 diameters long. However, the boundarylayers are turbulent, and the actual velocity thickness can be such that opposing boundary-layers touch. Such conditions could cause serious temporal and spatial variations in the nozzle test flow, particularly if the supply-tube $M$ is high. It was shown that the two-stage design allows the use of reduced diameter supply tubes to drive a nozzle with a fixed diameter. For the same test time, the supply tube for this configuration will therefore be many diameters longer than that for a standard Ludwieg tube. This will increase the importance of the viscous effects, ultimately causing the supply-tube flow to assume some of the features of a developed pipe flow.

Analysis of the supply-tube flow starts with a consideration of the turbulent wall-boundary layer driven by an expansion wave. Simplifying assumptions are needed in order to make the problem tractable. The principal assumption in Becker's analysis is that the density is constant across the boundary layer, while Mirels ${ }^{13}$ assumes that the expansion wave has zero thickness. The results of these two analyses are presented in Fig. 6. Here $\delta$ is the boundary-layer thickness at the diaphragm end of the supply tube when the expansion wave has reached the closed end. It is plotted in terms of $P_{4}$ and $l$ vs $M$ for nitrogen at $300^{\circ} \mathrm{K}$. The assumptions used in developing the models are more nearly correct at low $M$, and this is reflected in the relative agreement between the two calculations near $M=0$. At higher values of $M$ the disagreement becomes greater, as does the uncertainty that either model is correct. The boundary-layer becomes more complex as the expansion wave reflects off the closed end. Further complication is to be expected for large aspectratio tubes, for which boundary-layer analysis ultimately breaks down.

The viscous-induced nonuniformities in shock tubes and shock tunnels are similar to those that occur in Ludwieg tubes. The non-steady boundary layer behind a travelling shock wave is reasonably well understood, and the effect on flow properties can be estimated; however, reflected shock tunnels involve complicated reflected-shock boundary layers that can introduce 


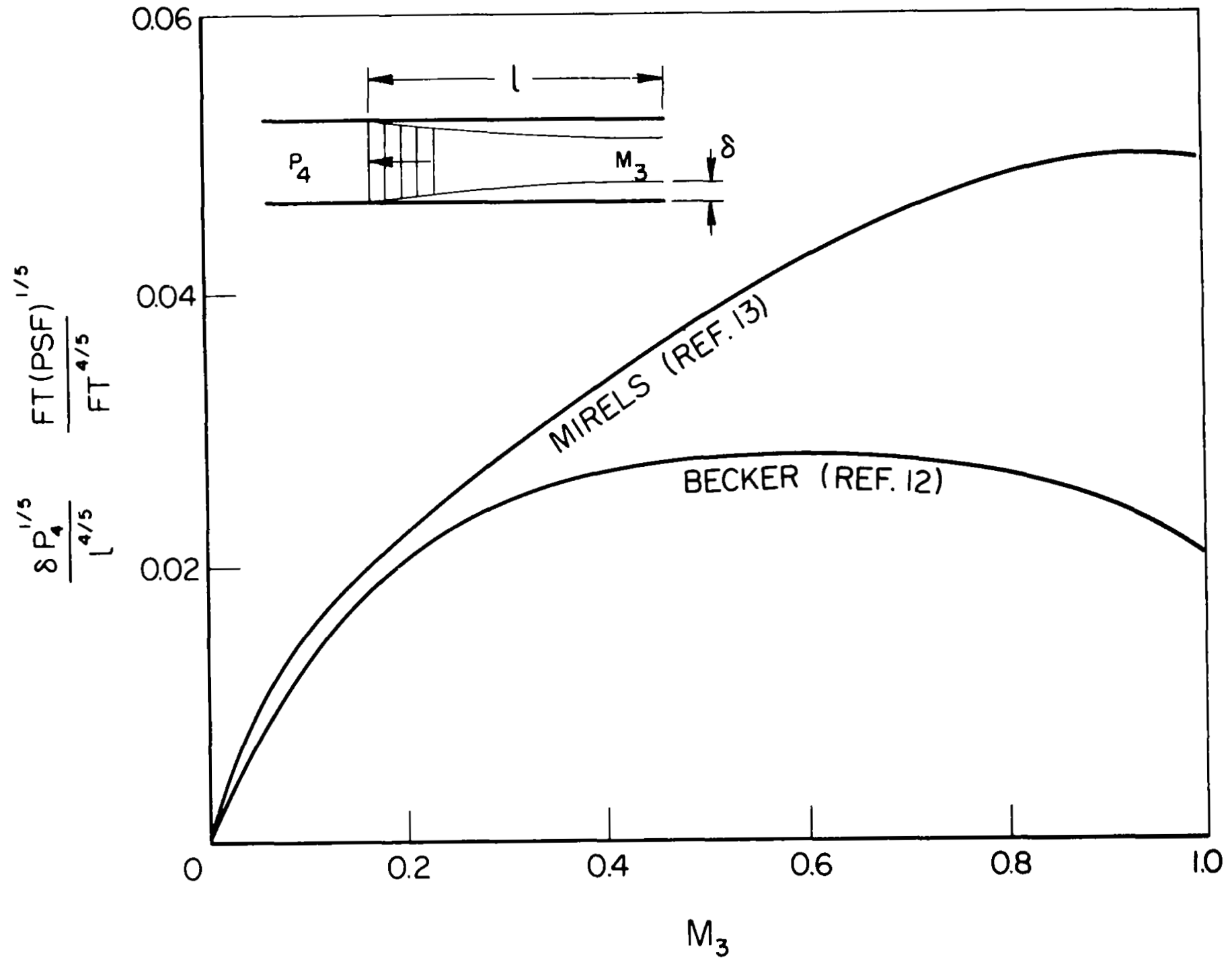

Figure 6. Turbulent Boundary-Layer Thickness at Origin of a Centered Expansion Wave (Nitrogen; $\mathrm{T}_{4}=300^{\circ} \mathrm{K}$ ) 
nonuniformities similar in magnitude to those expected in a Ludwieg tube. Fortunately, the shock Mach numbers proposed for the present application are low enough that the phenomena of reflected shock bifurcation will not occur; thus a major source of nonuniformity in reservoir flow is removed. 


\section{DISCUSSION}

The previous sections have dealt with the design and expected performance of quasi-steady facilities. A small research tube has been put together at the University of Washington in order to look further into the general applicability of quasisteady facilities for the study of high Re flows. A M = 3 nozzle is used which is fed by a 20-foot supply tube equipped with various orifice plates. The nozzle test section is $3 \times 4$ inches in cross section. The test flow dumps into 20 feet of rectangular tubing.

Measurements have been made of the pressure history in the supply tube. These are being used to check an analytical model developed to explain the pressure drop for various operating conditions. Actual measurements of the non-steady expansion wave boundary-layer will be undertaken only if unforeseen difficulties are experienced in understanding the supply tube nonuniformities. Preliminary shadowgraphs have shown the flow starting details. The starting times for two-stage nozzles are in rough agreement with the predictions.

Considerable work remains to be done before the questions raised in the body of this report are satisfactorily answered. More sensitive measurements will be needed, such as may be provided by hot wire, interferometer, or laser scattering techniques. Once the flow starting times and flow quality have been carefully established, the experiments will be directed to determining the starting time for the flow about models expected to show Resensitivity. Studies of high-Re aerodynamics will then be undertaken, ultimately using the University of Washington 7-inch high pressure shock tube to extend the range of $\operatorname{Re}$ available. 


\section{REFERENCES}

1. Ludwieg, H., "Der Rohrwindkanal," Zeitschift für Flugwisserschaften, Jahrgang 3, Heft 7, 206, July 1955.

2. Cable, A. J. and Cox, R. N., "The Ludwieg Pressure Tube Supersonic Wind Tunnel," Aero. Quart., 143-157, May 1963.

3. Tamaki, F., "A Divergent Shock Tube for Obtaining Supersonic Flows," I. Phys. Soc. Japan, Vol. 2, No. 4, April 1956.

4. Falk, T. J., "A Tube Wind Tunnel for High Reynolds Number Supersonic Testing," U. S. Air Force ARL 68-0031, February 1968.

5. Hottner, T., "Modellversuche an einer Speicherrohr-Anordnung fü einen Hyperscha11-Rohrwindkanal," German AVA Report 67A04, 1967.

6. Davis, J. W. "A Shock-Tube Technique for Producing Subsonic, Transonic and Supersonic Flows with Extremely High Reynolds Numbers," AIAA Preprint, 1968.

7 Russe11, D. A. and Hertzberg, A., "Shock-Tube Configurations for the Study of Non-equilibrium Steady Expansions," Bulletin Amer. Phys. Soc. Vo1. 13, No. 11, 1602, 1968. See also Russe11, D. A. "Methods of Extending the Use of Shock Tubes for Gain Studies," NASA Hdqtrs. Conference on Gas Laser Research, Washington, D. C., July 1968. (Proceedings to be published as NASA Special Publication.)

8. Wagner, H., "Uber die Entstehung des dynaischen Auftriebes von Tragglug1n," Ztschr. f. angew Math. und Mech., Band 5, Heft 1, 17-35, 1925.

9. Stewartson, K., "On the Impulsive Motion of a Flat Plate in a Viscous Fluid," Quart. Journal Mech. ㅌ Applied Math., Vol. IV, Pt. 2, 182-198, 1951 .

10. Davies, W. R. and Bernstein, L., "Heat Transfer and Transition to Turbulence in the Shock-Induced Boundary Layer on a Semi-Infinite Flat P1ate," J. F1uid Mech. Vo1. 36, Pt. 1, 87-112, 1969.

11. Willmarth, W. W. and Enlow, R. L., "Aerodynamic Lift and Moment Fluctuations of a Sphere," J. Fluid Mech. Vo1. 36, Pt. 3, 417-432, 1969.

12. Becker, E., "Unsteady Boundary Layer Behind Compression Shocks and Expansion Waves," Progr. Aeron. Sci. 1, 104-173, 1961.

13. Mirels, H., "Boundary Layer Behind Shock or Thin Expansion Waves Moving into Stationary Fluid," NACA Tech. Note 3712, 1956. 